\title{
Evaluating a remote wetland functional assessment along an alteration gradient in coastal plain depressional wetlands
}

\author{
P.J. Backhaus, S. Lee, M. Nassry, G. McCarty, M. Lang, and R.P. Brooks
}

\begin{abstract}
As anthropogenic disturbance continues to degrade wetland condition in many geographic areas, it is imperative to inventory wetland functions to monitor potential loss of associated ecosystem services. Field-based functional assessments are resource intensive, prohibiting their widespread application at landscape scales. This obstacle can be avoided by basing functional assessments on publicly available remote sensed data. This pilot study examined the use of Watershed-based Preliminary Assessment of Wetland Function (W-PAWF) in the assessment of wetland restoration sites. W-PAWF was used to assess 15 depressional wetlands in the US Mid-Atlantic Coastal Plain. These sites spanned a human alteration gradient (i.e., natural wetlands, restored wetlands, and prior-converted croplands) to determine the sensitivity of the assessment method to variation in the assemblage and performance of wetland functions. Field-based rapid assessment methods were used to verify the W-PAWF assessment and detect potential functional gaps of importance to wetland restoration. Results indicate that W-PAWF can differentiate varying levels of restoration condition, but refinement will be necessary to assess functional restoration goals related to biogeochemistry and water quality. An evaluation of the field-based methods and an alternate remote functional assessment system suggest the potential for these functional characteristics to be incorporated in future iterations of the W-PAWF.
\end{abstract}

Key words: HGM — LLWW—-rapid assessment—remote sensing-W-PAWF

\begin{abstract}
Wetlands are known to be critical sources of ecosystem services, but they continue to be degraded or lost due to anthropogenic activities. Wetlands provide unique ecosystem services unavailable from other habitats and provide more of these services per unit area when compared to other ecosystem types (Costanza et al. 1997). Dahl (1990) estimated the loss of wetland area in the contiguous United States to be greater than 50\% since European colonization. Though the rate of loss has considerably slowed in recent decades (Dahl 2000, 2011), with a small net gain observed over some years (Dahl 2006), the net area of lost wetlands is still substantial. The degradation of existing wetlands further compounds this loss, decreasing the ability of these systems to provide the same assemblage or level of performance of ecosystem services
\end{abstract}

Received June 1, 2019; Revised November 18, 2019; Accepted January 27, 2020. capacity of wetlands, or even prohibit them from performing these functions.

Wetland restoration is a common practice typically implemented to restore or enhance wetland structure and functions where degradation has occurred (Mitsch and Gosselink 2000; Zedler and Kercher 2005). With this objective in mind, the success or failure of a restoration project can be observed and quantified by performing field-based functional assessments pre- and postrestoration, with additional monitoring occurring in subsequent years to assess more gradual functional shifts through time (Kentula et al 1992; Brooks and Gebo 2013). These assessment methods, ranging from rapid to intensive (commonly referred to as Level 2 assessment and Level 3 assessment, respectively), vary in time and material cost. While these functional assessments can be deployed on an individual wetland basis, attaining the functional restoration goals of a single site does not readily translate to overall wetland functional enhancement at watershed scales. Sites selected for restoration may already have adequate functional capacity relative to other disturbed wetlands in the watershed or the functions selected for enhancement may not represent the assemblage or level of performance of the wetland's predisturbance conditions. To gain a more holistic understanding of current wetland functions and change over time, assessments must be conducted at the watershed scale.

The relatively large cost and time investment necessary to implement intensive and/ or rapid field-based assessments prohibit the widespread sampling of wetlands when assessing broad geographic areas. This makes

Ecological functions within wetlands vide ecosystem services that benefit people (Millennium Ecosystem Assessment 2005). Wetland functions vary throughout a watershed based largely on landscape position, wetland type, and disturbance (Brinson 1993a). These factors influence which assemblage of functions exist and at what capacity these functions operate (Brinson 1993a; Mitsch and Gosselink 2000). For example, riverine wetlands may facilitate flood attenuation; however, those along low order headwater streams are likely to perform this function at a lower level than those along higher order streams. Anthropogenic development or other stressors may degrade the

Peter J. Backhaus is a doctoral candidate at Riparia, Department of Geography, The Pennsylvania State University, University Park, Pennsylvania. Sangchul Lee is an assistant professor with the School of Environmental Engineering, University of Seoul, Dongdaemun-gu, Seoul, South Korea. Michael Nassry is an assistant research professor at Riparia, Department of Geography, The Pennsylvania State University, University Park, Pennsylvania. Greg McCarty is a research soil scientist at the Hydrology and Remote Sensing Laboratory, USDA Agricultural Research Service (ARS), Beltsville, Maryland. Megan Lang is chief scientist, National Wetlands Inventory, US Fish and Wildlife Service, Falls Church, Virginia. Robert P. Brooks is professor emeritus of geography at Riparia, Department of Geography, The Pennsylvania State University, University Park, Pennsylvania. 
the use of landscape-scale methods that rely on readily available geospatial data (Level 1 assessment) an attractive option. The National Wetlands Inventory geospatial data set (NWI), managed by the US Fish and Wildlife Service (USFWS), is the most widely available spatially and categorically detailed synoptic data set on wetlands in the United States. The NWI uses the Federal Geographic Data Committee (FGDG 2013) classification standard for wetlands and deepwater habitats, a revision of the prior Cowardin et al. (1979) classification system. The NWI classifies wetlands by their biological and physical characteristics (i.e., vegetation, soils, hydrology, and landscape). Although the NWI is the most categorically detailed national wetland geospatial data set, these categories are not readily translated into functions, as they represent only a portion of wetland characteristics and variation. This limitation can be overcome by implementing an approach that adopts a classification system developed specifically to assess a broad range of wetland functions, paired with information on relative wetland condition.

Recognizing that attributes beyond those available in the NWI would be required for watershed functional assessment, Brinson developed the hydrogeomorphic (HGM) wetland classification. This approach uses "geomorphic, physical, and chemical descriptors" (Brinson 1993b) to describe a wetland's landscape position, water source, and hydrodynamics, allowing one to then assign functions to combinations of these characteristics. Though a function may occur in multiple locations on the landscape, HGM classifications assign varying levels of functional performance to wetlands in different landscape positions (Brinson 1995).

Building off of Brinson's methods, Tiner developed the Watershed-based Preliminary Assessment of Wetlands Functions (W-PAWF; Tiner 2003). This assessment method leverages the HGM approach with the NWI. First, Landscape position, Landform, Water flow path, and Waterbody type (LLWW) descriptors are appended to NWI classifications (this is sometimes termed an "NWI+" inventory) to add HGM characteristics (Tiner 2014). With these characteristics in place, an assemblage of functions and their potential performance significance (high, moderate, or absent) can be assigned to a wetland. The W-PAWF can assess up to 10 functions (table 1), generalized for use at a landscape scale,

\section{Table 1}

W-PAWF functions sorted into their functional categories for scoring.

\begin{tabular}{ll}
\hline Functional category & W-PAWF function \\
\hline Hydrology & Surface water detention \\
& Coastal storm surge detention \\
& Streamflow maintenance \\
& Shoreline stabilization \\
\hline Biogeochemistry & Nutrient transformation \\
& Retention of sediments and other particulates \\
\hline Biodiversity & Provision of habitat for fish and other aquatic animals \\
& Provision of waterfowl and waterbird habitat \\
& Provision of other wildlife habitat \\
& Conservation of biodiversity
\end{tabular}

but is intended to be a practical observation of potential wetland functional capacity and does not capture landscape interactions or specific processes underlying evaluated functions. The use of reference wetlands can enhance either method by providing intensively studied sample levels of functions for potential comparison to similar wetlands catalogued in later assessments. This allows the functional performance of remotely detected wetlands to be estimated without the need for extensive fieldwork.

The limited nature of functions evaluated by W-PAWF may not adequately assess the specific functional goals targeted by a restoration and the range of conditions present in a restored wetland as it develops over time. To address this issue, this pilot study evaluated the use of the remote W-PAWF method as a means of predicting the functional variety and performance level of restored wetlands. The remote assessment was conducted on sites along a human alteration gradient, including not only restored wetlands, but naturally occurring wetlands and prior-converted croplands (PCC; historical wetlands that are actively farmed). Additionally, a set of fieldbased rapid functional assessment methods were applied to these remotely assessed sites to determine the efficacy of the W-PAWF assessment results and detect potential functional gaps in the remote assessment.

Study Area. The Delmarva Peninsula has been the focus of previous wetland functional assessments and modeling (Tiner 2005; Weller et al. 2007; Whigham et al. 2007; Lang et al. 2015). Much of this area of Coastal Plain has been converted from forests to predominantly agricultural landscapes since European settlement, leading to numerous water-related issues within the peninsula and influences on the Chesapeake
Bay (e.g., eutrophication, lowered water tables, and flooding). The Watershed Component of the National Conservation Effects Assessment Project (CEAP) was implemented in the Choptank River watershed on the Delmarva Peninsula by USDA Natural Resources Conservation Service (NRCS) largely to quantify the effectiveness of conservation practices in reducing these water-related problems. This watershed is a designated Long-Term Agricultural Research (LTAR) watershed by the USDA's Agricultural Research Service (ARS). In addition, the peninsula comprises a portion of the USDA NRCS Mid-Atlantic Regional Wetland Component of the National CEAP (CEAP-Wetlands).

One focus of CEAP-Wetlands is to determine the role of wetland functions in improving water quality (Lang et al. 2015). The project established three levels of wetland management across a human alteration gradient: PCC, restored wetland, and natural wetland. PCCs are defined by the Swampbuster provision of the 1985 Food Security Act as wetlands on agricultural lands converted from wetland to cropland prior to December 23,1985, that have been under agricultural production during most years since that time. While typically drained, these areas continue to exhibit some degree of wetland characteristics when compared to adjacent uplands (Lang et al. 2015). These unrestored areas are highly impacted by agricultural practices within or adjacent to the PCC and are the most human-altered sites. Restored wetlands included in this study were altered per the USDA NRCS Practice Standard for Wetland Restoration (Code 657) to enhance wetland functions to levels close to their predisturbance condition. Natural wetlands were assumed to be near 


\section{Figure 1}

Examples of a (a) prior-converted cropland, (b) restored wetland, and (c) natural wetland in the study area.

(a)

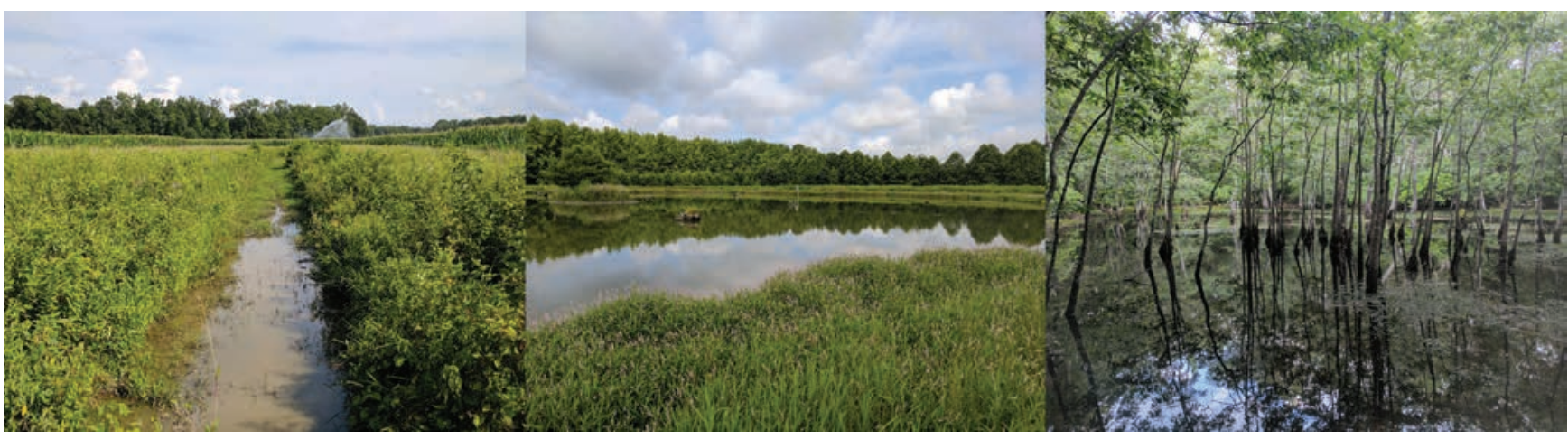

their expected natural condition and level of functioning, were not restored, and had the lowest level of human alteration. Example photos of a wetland in each level of condition are displayed (figure 1). This study compared the differences in results among the set of restored wetlands and among the three categories of the alteration gradient to test the sensitivity of the W-PAWF to wetland restoration and degradation. The use of unrestored wetlands provided domains in which the restored wetlands' results could be compared to the results of the highly altered PCC conditions and relatively undisturbed conditions of natural wetlands. It was hypothesized that higher levels of human alteration would result in a smaller variety of functions and a lower level of performance of these functions.

\section{Materials and Methods}

Site Descriptions. The study sites were located on the Coastal Plain of the Delmarva Peninsula (figure 2). This landscape is dominated by croplands (predominately corn [Zea mays] and soybean [Glycine max]) interspersed with a matrix of forests and a minor component of urban development. Extensive agricultural ditching and groundwater-sourced irrigation are implemented throughout the agricultural area.

Fifteen freshwater depressional wetlands sites were selected within Maryland and Delaware from a prior CEAP-Wetlands study of 48 sites (Lang et al. 2015). The sites were located within adjacent watersheds and occupied the flat terrain of the Coastal Plain. The wetlands were classified as depressions in the HGM classification system for the MidAtlantic (Brooks et al. 2011) and represented all three levels of the alteration gradient: five PCCs, six restored wetlands, and four natural wetlands. The use of depressional wetlands controlled for potential variation, as wetlands with differing HGM classifications may be affected differently by similar stressors. The wetlands' similar position on the landscape, water source, and hydrodynamics also controlled for natural variations found in other HGM classifications (e.g., varying levels of

\section{Figure 2}

Aerial imagery of the study area in 2017 (USDA National Agriculture Imagery Program). The boundary of the Choptank River watershed (HUC 02060005) is displayed for reference.

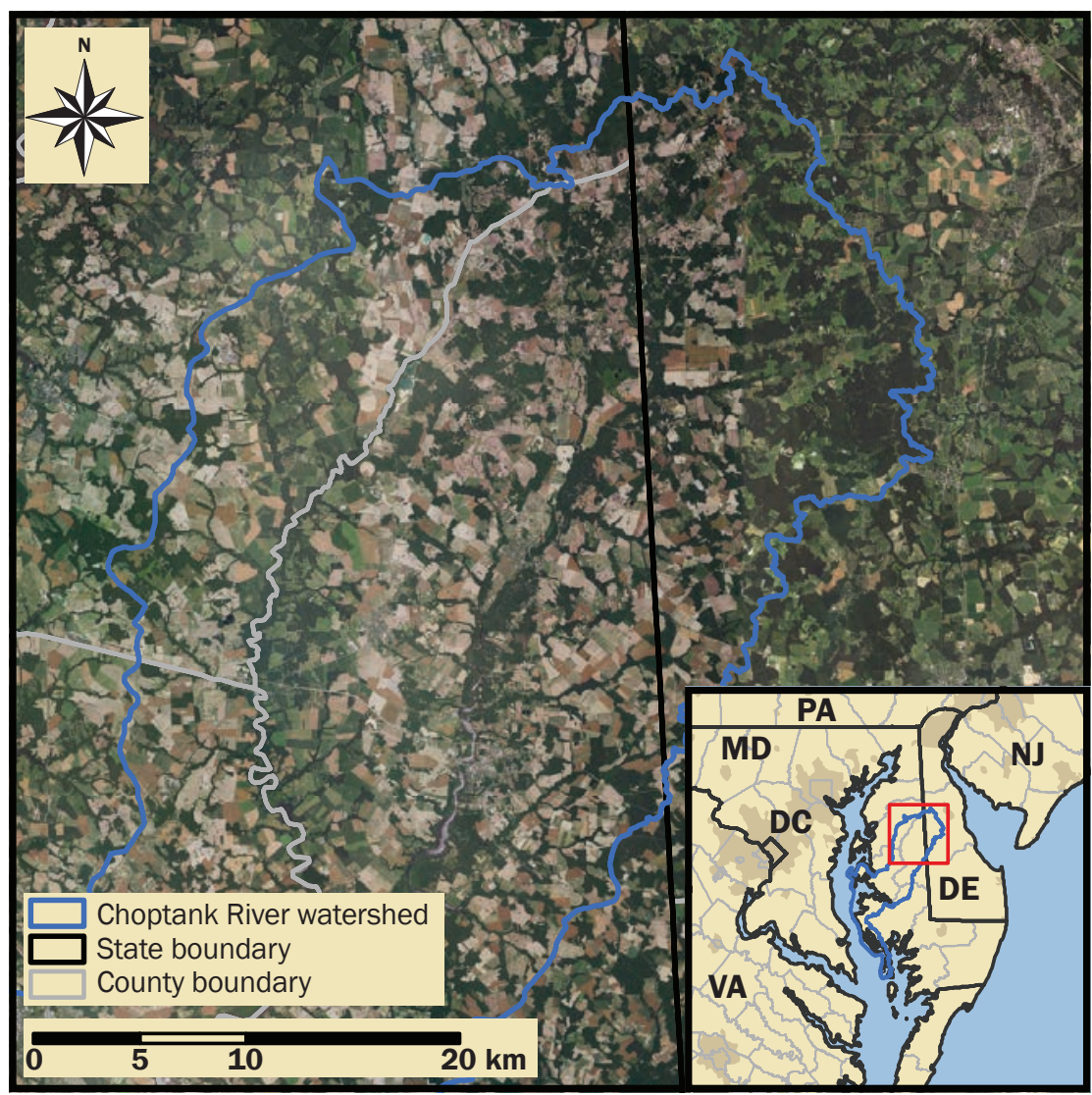


flooding may transport or store nutrients and sediments at different levels even when wetlands are connected to the same throughflow).

Site visits occurred in July of 2017. Total precipitation in the month preceding the visits was $93 \mathrm{~mm}$, with $55 \mathrm{~mm}$ of precipitation falling within a week prior to the first site visit (Menne et al. 2012a, 2012b). Natural wetlands were typically forested, with one site containing a sedge meadow and an inclusion of scrub-shrub. One natural site was not inundated at the time of the visit. Restored sites varied in characteristics: two were primarily open water, two were dominated by Typha latifolia, one was predominately mixed emergent herbaceous vegetation, and one site was recently drained for agricultural use, but retained areas with restored wetland characteristics. PCCs were located within agricultural fields. Most PCCs were ditched, with steep banks covered by herbaceous vegetation and some woody shrubs and saplings. The remaining PCCs were shallow swales: one acted as a windbreak with shrub and tree cover, the other topographically draining a low point of a soybean field with herbaceous vegetation cover and evidence it had been treated with herbicide. Mean wetland area was 0.8 ha \pm 1.3 ha in natural wetlands, 1.0 ha \pm 0.7 ha in restored wetlands, and 3.8 ha \pm 3.5 ha in PCCs.

Remote Functional Assessment. The assemblage and performance level of wetland functions were remotely determined using W-PAWF (Tiner 2003). This system was developed for use in the northeastern United States, and can evaluate up to 10 wetland functions on a landscape level. It was successfully employed in an assessment of the nearby Nanticoke River watershed (Tiner 2005), and thus, deemed appropriate for these Coastal Plain wetlands. Two of the $10 \mathrm{~W}-\mathrm{PAWF}$ functions are not directly applicable to this assessment, as they are intended for estuarine wetlands.

To perform the assessment, LLWW descriptors were appended to the wetland polygons provided by the CEAP-Wetlands study (Lang et al. 2015). These descriptors were determined through the dichotomous key and mapping code system of the LLWW system (Version 3.0; Tiner 2014) using remotely sensed aerial imagery, including Light Detection and Ranging (LiDAR) data. An example of LLWW descriptors and mapping codes can be found in figure 3 , demonstrating the potential variety of

\section{Figure 3}

Application of Landscape position, Landform, Water flow path, and Waterbody type (LLWW) to a fictional, nontidal landscape. Labels represent the combination of LLWW mapping codes present in each wetland, including lentic (LE), lotic river (LR), lotic stream (LS), and terrene (TE) landscape positions; basin (BA), floodplain (FP), fringe (FR), and slope (SL) landforms; isolated (IS), outflow (OU), and throughflow (TH) water flow paths; and lake (LK), pond (PD), and river (RV) waterbodies.

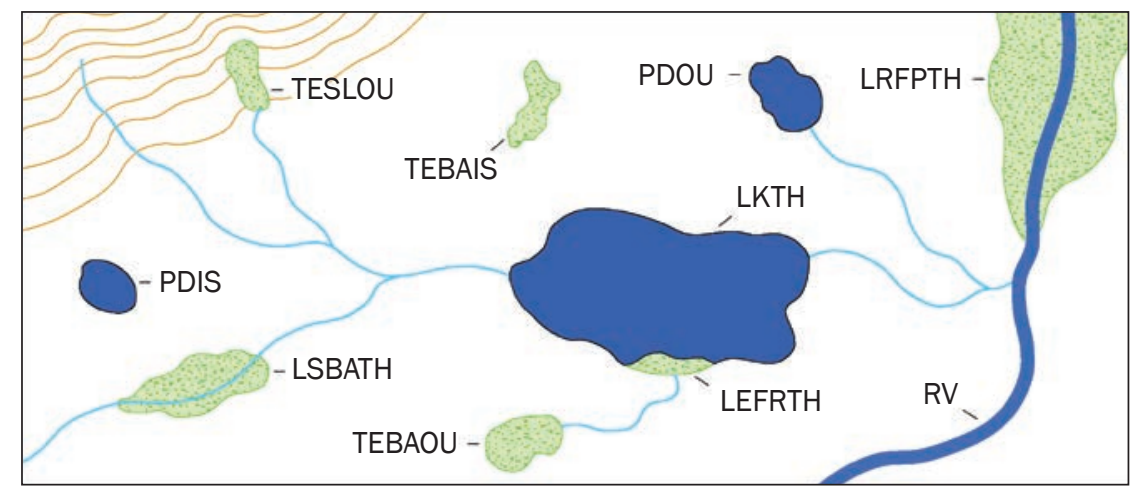

descriptors present in a single landscape. Each of the $10 \mathrm{~W}-\mathrm{PAWF}$ functions are related to combinations of LLWW descriptors, NWI classifications, and remote sensing data interpretations to provide "high" and "moderate" potential performance ratings for each wetland (Tiner 2003).

A simple index was created to interpret the results of the W-PAWF. This index provides an easily interpreted result by which the functional variety and performance level of wetlands can be compared. As each wetland function was assessed, a score of 1.0 was assigned to "high" W-PAWF potential performance ratings, 0.5 to "moderate" W-PAWF potential performance ratings, and 0.0 for functions absent in the wetland (this category also includes functions that are present at a performance level deemed negligible to the assessment at a landscape scale, and thus excluded from the other performance rating levels and considered absent from the wetland). These values were used to differentiate the two levels' performance significance indicated by W-PAWF and were not intended to be representative of quantitative or magnitude differences of functional performance. To relate the various functions and simplify the results of the assessment, the functions were divided into three functional categories: hydrology, biogeochemistry, and biodiversity (table 1). Each category was scored as the sum of each individual function's score for that wetland. A total index score for each wetland was also computed, using the sum of the three categories. The resulting score represents the variety of functions in the wetlands adjusted for performance level (i.e., lower scores for moderate potential ratings or absent functions).

Field Assessments. A set of rapid field assessment methods was conducted at each site to compare to the results of the W-PAWF and identify any functional gaps not addressed by W-PAWF that may be considered important for assessing restored wetlands. These methods were derived from the Stream-Wetland-Riparian Index (SWR) sampling protocol (Brooks et al. 2009), the Level 3 Wetlands Sampling Protocol from Brooks (2004), and the Unified Mid-Atlantic Rapid Assessment Protocol for Wetlands (UMA RAP; Brooks et al. 2013), all developed and tested in the Mid-Atlantic Region.

The SWR protocol included a vegetation assessment and stressor checklist. Given the depressional, and often geographically isolated, classification of the wetlands, the protocol was adjusted to focus on wetlands by removing sampling of stream and riparian areas. The vegetation assessment consisted of an inventory of species and their respective percentage of cover at three vertical strata: herbaceous, shrub and understory tree, and tree. The stressor checklist was comprised of potential disturbances to the wetland and were divided into 10 categories: hydrologic modification, sedimentation, dissolved oxygen $(\mathrm{O})$, contaminant toxicity, vegetation alteration, eutrophication, acidification, turbidity, thermal alteration, and salinity. Stressors were evaluated within each wetland and separately within a $100 \mathrm{~m}$ buffer surrounding the wetland. The numbers of stressors observed 
were summed to create a stressor score for both assessment areas, where a higher count generally indicates a higher level of human disturbance degrading the wetland.

Methods from the Level 3 Wetlands Sampling Protocol (Brooks 2004) included microtopographic transects, coarse woody debris (CWD) transects, a set of habitat suitability index (HSI) models for 10 wetland species (Brooks and Prosser 1995; Brooks and Gebo 2013), and the characterization of soils both in the field and laboratory. Both microtopography and coarse woody debris were measured along the same set of transects. Microtopographic depressions were recorded along the transects in semiquantitative depth categories. The increasing presence of microtopography creates more functional microhabitats and moisture gradients within a wetland. CWD was recorded along the same transects, with debris $>1 \mathrm{~m}$ in length recorded in diameter categories. CWD functions as microhabitat within a wetland and provides nutrient storage and release over time. The HSI models evaluated 10 wetland-dependent wildlife species with measures ranging from 0.0 to 1.0 (unsuitable to optimal habitat, respectively). Focal species cover a gradient of preferred habitat cover, ranging from open water and herbaceous cover to scrub-shrub and forested vegetation, and act as a proxy for a biodiversity function.

The UMA RAP methods consisted of an additional stressor checklist and a semiquantitative measurement of invasive cover. The stressor checklist consists of the same stressor categories as the SWR sampling protocol, but differs in several of the specific stressors evaluated. The set of invasive species evaluated for cover were developed for use in the Mid-Atlantic Region and are available in the protocol (Brooks et al. 2013).

Additionally, soil samples were collected to inform the results of both the field based and remote assessments. A soil penetrometer (Eijkelkamp Hand Penetrometer Set, Eijkelkamp, The Netherlands) was used to measure soil penetration resistance at the depths of 10,20 , and $30 \mathrm{~cm}$ below the land surface at randomly selected points at each site. The measured penetration resistance matched well with the soil characteristics shown in the Soil Survey Geospatial (SSURGO) database (Lee et al. 2018). There were 73 data measurement points among the wetland sites: 22 points for natural wetlands, 28 points for the restored wetlands, and 23 points for the PCCs. Soil compaction values were compared by wetland alteration level. Additionally, a set of soil samples was collected at depths of 5 and $20 \mathrm{~cm}$, with 25 , 30 , and 35 soil samples collected in natural, restored, and PCC sites, respectively. These samples were analyzed by the USDA ARS Pasture Systems and Watershed Management Laboratory for Mehlich and total soil phosphorus $(\mathrm{P})$ content. Prior to analysis, air dried samples were sieved through a $2 \mathrm{~mm}$ mesh. Total P was extracted by US Environmental Protection Agency (USEPA) standard method 3050b (Kimbrough and Wakakuwa 1989) aqua regia digestion while Mehlich 3 solution (Mehlich 1984) was used to extract Mehlich P. Both extracts were analyzed by inductively coupled plasma optical emission spectrometry (Agilent 720 ICP-OES) Significance was tested using Mood's Median test, a nonparametric method to specifically test difference in median values of two or more groups, using R (R Core Team 2013).

This collection of field-based methods was used to determine the efficacy of the results of W-PAWF assessment and scoring index when possible by comparing the patterns of functional performance of the results with those of the remote assessment (e.g., HSI models as a proxy for the biodiversity functions and scores of the index). The field-based methods also provided functions or indicators of functional performance not included in the W-PAWF, and were evaluated for their potential to be remotely sensed in future landscape-scale geospatial assessments.

Data Analysis. Results of the SWR vegetation sampling were assessed using a Floristic Quality Assessment Index (FQAI). This bioassessment tool measures a plant community's habitat quality using a coefficient of conservatism $(C)$ to weight species richness This coefficient is a 0 to 10 score assigned to plants within a specific geographic region, where generalist species that can tolerate disturbance receive a low score and specialist species requiring a relatively unaltered environment are assigned a higher score. Plants considered exotic within the region are assigned a score of 0 . To include nonnative species and remove the bias of high quality, low species richness sites, an Adjusted FQAI was computed using equation 1 (Miller and Wardrop 2006):

$I^{\prime}=\left(\frac{\bar{C} \times \sqrt{N}}{10 \times \sqrt{N+A}}\right) \times 100$ where $I^{\prime}$ is the Adjusted FQAI, $\bar{C}$ is the mean coefficient of conservatism, $N$ is the number of native species, and $A$ is the number of nonnative species. Coefficient of conservatism values were obtained from the Mid-Atlantic Floristic Quality Assessment Project (Chamberlain and Ingram 2012), using Coastal Plain values from the MidAtlantic Wetlands Workgroup's online Floristic Quality Index Calculator (MAWWG n.d.). The FQAI has previously been used as a proxy for wetland alteration gradients in adjacent states (Miller et al. 2006; Chamberlain and Brooks 2016).

The stressor checklists of the SWR and UMA RAP protocols evaluated the wetland assessment area and its surrounding $100 \mathrm{~m}$ buffer. To supplement these data and account for more of the surrounding landscape, a Landscape Development Intensity (LDI) index was computed within a $1 \mathrm{~km}$ radius of each wetland's centroid. This ecological condition assessment weighs land use as a proxy for human disturbance using equation 2 (Brown and Vivas 2005):

$\mathrm{LDI}_{\text {Total }}=\sum \% \mathrm{LU}_{i} \times \mathrm{LDI}_{i}$,

where $\mathrm{LDI}_{\mathrm{Tota}}$ is the $\mathrm{LDI}$ score for a site, $\% \mathrm{LU}_{i}$ is the percentage of total area of land use $i$ in the assessment area, and $\mathrm{LDI}_{i}$ is the landscape development intensity coefficient for land use $i$. Land cover uses were derived from the Multi-Resolution Land Characteristics Consortium National Land Cover Database (NLCD) 2011.Values for the landscape development intensity coefficient range from 1.00 for water, wetlands, and forest to scores of 8.97 for high intensity residential and commercial/industrial areas (table 2; Brown and Vivas 2005). Lower LDI Total $_{\text {scores represent }}$ forested, low disturbance conditions, while higher scores indicate more intense levels of human impacts. Additionally, the percentage forest area, percentage agricultural area, percentage developed area, and road density $(\mathrm{km}$ $\mathrm{km}^{-2}$ ) within a $1 \mathrm{~km}$ radius around the wetland's centroid were independently analyzed among the alteration gradient categories. The areas were calculated from the NLCD 2011 classes and values (table 2), grouping the forest classes (41, 42, and 43) for forest area, the cultivated crops class (82) for agricultural area, and the development classes $(21,22,23$, and 24) for developed area. Road distances were derived from the US Census Bureau 2017 TIGER database. 
Table 2

Landscape Development Intensity (LDI) coefficients (LDI) for the National Land Cover Database (NLCD) 2011 land use classes present in the areas analyzed with the LDI. Values adopted from Brown and Vivas (2005).

\begin{tabular}{ll}
\hline NLCD 2011 land use class-Value & LDI coefficient \\
\hline Water & \\
Open water-11 & 1.00 \\
Development & 7.18 \\
Developed, open space-21 & 7.18 \\
Developed, low intensity-22 & 8.97 \\
Developed, medium intensity-23 & 8.97 \\
Developed, high intensity-24 & \\
Barren & 7.81 \\
Barren land (rock/sand/clay)-31 & \\
Forest & 1.00 \\
Deciduous forest-41 & 1.00 \\
Evergreen forest-42 & 1.00 \\
Mixed forest-43 & \\
Shrubland & 1.00 \\
Shrub/scrub-51 & \\
Herbaceous & 3.31 \\
Grassland/herbaceous-71 & \\
Planted/cultivated & 3.31 \\
Pasture/hay-81 & 5.77 \\
Cultivated crops-82 & \\
Wetlands & 1.00 \\
Woody wetlands-90 &
\end{tabular}

\section{Table 3}

Results of the W-PAWF index scoring.

\begin{tabular}{lllll}
\hline Restoration level & Hydrology & Biogeochemistry & Biodiversity & Total index \\
\hline PCC & 1 & 1 & 0.5 & 2.5 \\
& 1 & 1 & 0.5 & 2.5 \\
& 1 & 1 & 0.5 & 2.5 \\
& 1 & 1 & 0.5 & 2.5 \\
Restored & 1 & 1 & 0.5 & 2.5 \\
\hline 1 & 1 & 0.5 & 2.5 \\
& 1 & 1 & 1 & 3 \\
& 0.5 & 1 & 1.5 & 3 \\
& 0.5 & 1 & 2 & 3.5 \\
Natural & 1 & 1 & 3 & 5 \\
& 1 & 1 & 3 & 5 \\
\hline
\end{tabular}

Note: PCC = prior-converted cropland.
One-way analysis of variance (ANOVA) was used between the three groups of the alteration gradient $[\mathrm{F}(2,12)]$ to evaluate the results of the W-PAWF, field-based assessment, and data analyses. These statistical analyses were performed using Minitab version 18.1 (Minitab Inc. 2017).

\section{Results and Discussion}

Remote Functional Assessment. Scores for the W-PAWF index were identical for the biogeochemistry category, but were significantly different for hydrology $(F=10.20, p$ $=0.003)$ and biodiversity $(F=14.40, p=$ $0.001)$ among the three levels of alteration (table 3). This is likely due to the assessment's inability to consider land use in contributing, downstream, or adjacent upland areas (Tiner 2003). Biodiversity scores had the greatest variance $\left(\sigma^{2}=1.067\right)$ of the functional categories. The total index score was found to be significantly different along the alteration gradient $(F=9.44, p=0.003)$ and a negative relationship was observed between index scores and increasing levels of alteration (figure 4). Restored wetlands had a higher coefficient of variation $(C V=23.39)$ than natural wetlands $(C V=20.00)$ or PCCs $(C V=7.35)$.

Field Assessments and Analyses. FQAI was found to significantly differ among the alteration gradient categories $(F=7.24, p$ $=0.009)$. Natural wetlands scored highest, indicating more narrow niche species, while PCCs were found to have a higher mean FQAI score $(\mu=25)$ than restored wetlands $(\mu=21$; figure 5$)$. Invasive plant cover increased with increasing levels of alteration, with an average cover of less than $5 \%$ in natural sites, $5 \%$ to $20 \%$ in restored sites, and $20 \%$ to $50 \%$ in PCCs.

The stressor checklists of the SWR and UMA RAP protocols yielded similar results. Within the wetland assessment areas, a positive relationship was observed between stressor score and increasing human alteration (figure 5). Differences among the three alteration conditions were significant in both the SWR $(F=5.43, p=0.021)$ and the UMA RAP $(F=14.08, p=0.001)$ protocols. While this positive relationship was observed in the buffer's stressor scores, differences in buffer stressor scores among the alteration levels were marginally significant for the SWR $(F=3.91, p=0.049)$ and not significant for the UMA RAP $(F=2.41, p$ $=0.132)$. This lack of significance between 


\section{Figure 4}

Boxplot of the total index score for each level of the alteration gradient. Boundaries of the boxes represent the $25^{\text {th }}$ and $75^{\text {th }}$ percentiles, the horizontal line within the box represents the median (median value for the natural and prior-converted cropland (PCC) alteration levels are the same as the percentile bounds), and " $x$ " marks represent the mean.

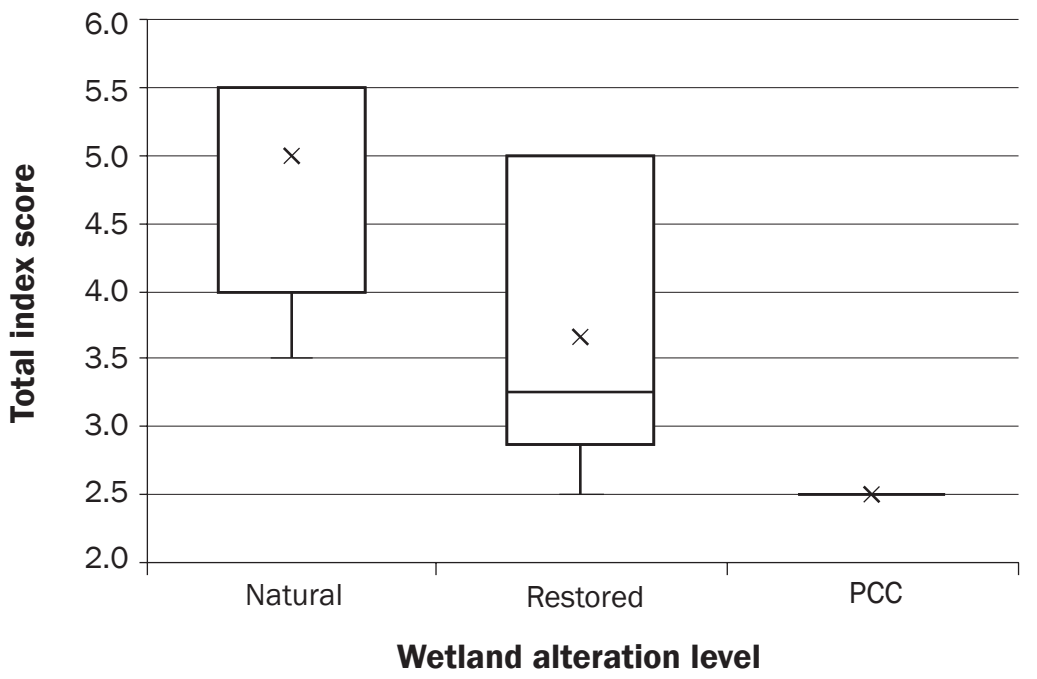

restoration conditions was observed in the surrounding landscape in the LDI $(F=0.81$, $p=0.469)$, percentage forest cover $(F=0.96$, $p=0.410)$, percentage agricultural cover $(F$ $=0.09, p=0.912)$, percentage development cover $(F=1.06, p=0.375)$, and road density $(F=1.67, p=0.229)$ analyses, as observed in table 4.

The microtopographic transects did not result in statistically significant differences within size classes or number of depressions recorded. However, restored wetlands had the highest number of counts in the smallest three depth classes $(0$ to $15 \mathrm{~cm}, 15$ to $30 \mathrm{~cm}$, and 30 to $45 \mathrm{~cm}$ ), while natural wetlands had the highest number of counts in the largest class $(>45 \mathrm{~cm})$. PCCs fell between the other wetland types in the 0 to $15 \mathrm{~cm}$ and 15 to 30 $\mathrm{cm}$ classes, but had the lowest counts at 30 to $45 \mathrm{~cm}$ and $>45 \mathrm{~cm}$ (there were no counts $>45 \mathrm{~cm}$ in PCCs). CWD counts along these transects resulted in significantly different counts along the alteration gradient for the 1 to $12 \mathrm{~cm}$ size class $(F=8.37, p=0.005)$ and 12 to $40 \mathrm{~cm}$ size class $(F=6.28, p=0.014)$, but not for debris $>40 \mathrm{~cm}(F=1.32, p=$ $0.303)$. The total average woody debris count for each transect also significantly differed by alteration level $(F=11.30, p=0.002)$. Natural wetlands contained the highest total average CWD count per transect with 45 counts, compared to restored wetlands with 6 and PCC with 8.
HSI models were analyzed for differences in patterns in potential habitat changes along the habitat gradient. Observing average scores by alteration gradient condition, natural sites provided higher quality habitat to species adapted to forested habitat (figure 6). PCCs provided open water habitat and some emergent habitat for wetland wildlife. Restored wetlands scored higher than PCCs for almost all species, but did not provide as high quality of forested habitat as natural sites.

Soil penetration resistance significantly varied by alteration level $(p<0.001)$. Soil resistance in natural wetlands was lower than restored wetlands and PCCs. Median values in restored wetlands (0.34) indicated a substantially greater resistance relative to natural wetlands (0.14). PCCs also had higher soil resistance than natural wetlands (figure 7). Total P (TP) significantly varied by alteration level $(p<0.05)$, while Mehlich P (MP) did not show significant differences $(p>0.1)$. Total $\mathrm{P}$ and MP in PCCs were substantially greater than natural and restored wetlands (figure 7). The median value for MP in both natural and restored wetlands in this study bordered on excess $\mathrm{P}$ availability $\left(50 \mathrm{mg} \mathrm{P} \mathrm{kg}^{-1}\right)$.

Assessment Interpretation. If human alteration and restoration had limited to no effect on wetland functions, we would expect to observe the same assemblage of functions and level of functional performance across all wetlands. This homogeneity would ren- der the W-PAWF concept ineffective, as the assessment and our index would provide the same result for each wetland. We were able to reject this hypothesis and demonstrate that the variety and level of performance of functions had a negative relationship with increasing human alteration. This assertion was supported by the remote functional assessment's results, where index scores decreased as the level of human alteration increased from natural wetlands to PCCs and functional scores varied within the restored wetland category. Analysis of the fieldwork data provided additional validation of this relationship; however, some inconsistencies were observed with restored and PCC wetlands.

FQAI was one such discrepancy, where two-thirds of restored wetlands scored below the range of PCC scores. The techniques used in restoration and the current management strategies of the two alteration levels may explain this deviation in plant communities and scores (Yepsen et al. 2014). Restoration design and management practices, such as relatively permanent inundation depth (e.g., older pond-like restorations), mowing near or within the restoration area, and the type of vegetative control following restoration could limit the establishment of some higher-scoring plant species. Though most of the PCC sites had been ditched, their banks were relatively undisturbed following this process. This may have allowed higher quality species to establish on the banks when left relatively undisturbed and in a zone with a more appropriate hydroperiod for these species. Invasive plant species in these sites, though covering a higher percentage of area than restored sites, were typically confined to the inundated beds of the channels. FQAI scores may have been skewed, where dominating agricultural monocultures of PCCs have less weight on the score than the variety of generalist species observed in restored sites.

Results of the stressor checklist were similar between the wetland assessment areas and their surrounding buffers; stressors increased as alteration increased. This complements the results of the W-PAWF along the alteration gradient. Though not statistically significant, the buffers had a similar pattern. The lack of significance may be due to the matrix of primarily agricultural land uses in the landscape. Though natural sites were predominately forested, they were still in the vicinity of nearby roads, mowed areas, and croplands. 
Figure 5

Boxplots of the (a) Floristic Quality Assessment Index (FQAI) results, (b) Unified Mid-Atlantic Rapid Assessment Protocol (UMA RAP) and Stream-Wetland-Riparian Index (SWR) stressor scores within the assessment area, and (c) UMA RAP and SWR stressor scores within the assessment area buffers. Boundaries of the boxes represent the $25^{\text {th }}$ and 75 th percentiles, the horizontal line within the box represents the median, and " $x$ " marks represent the mean.

(a)

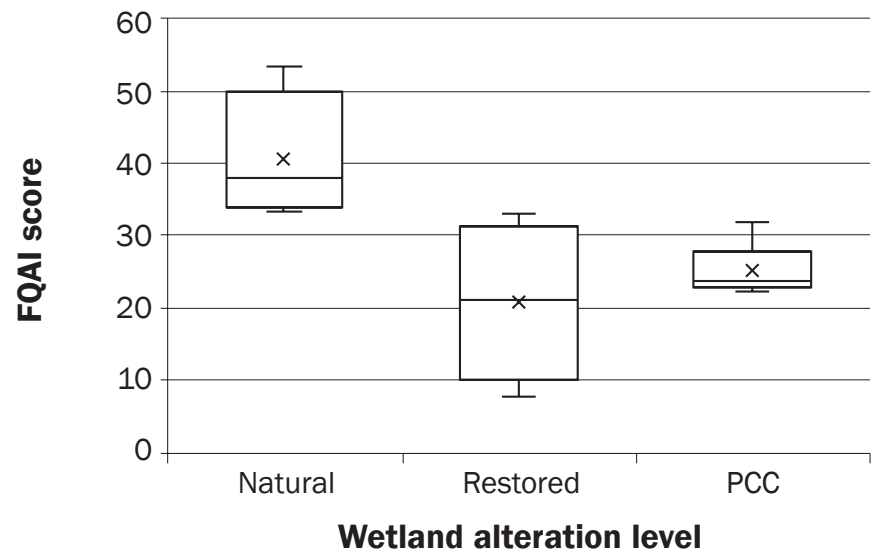

(b)

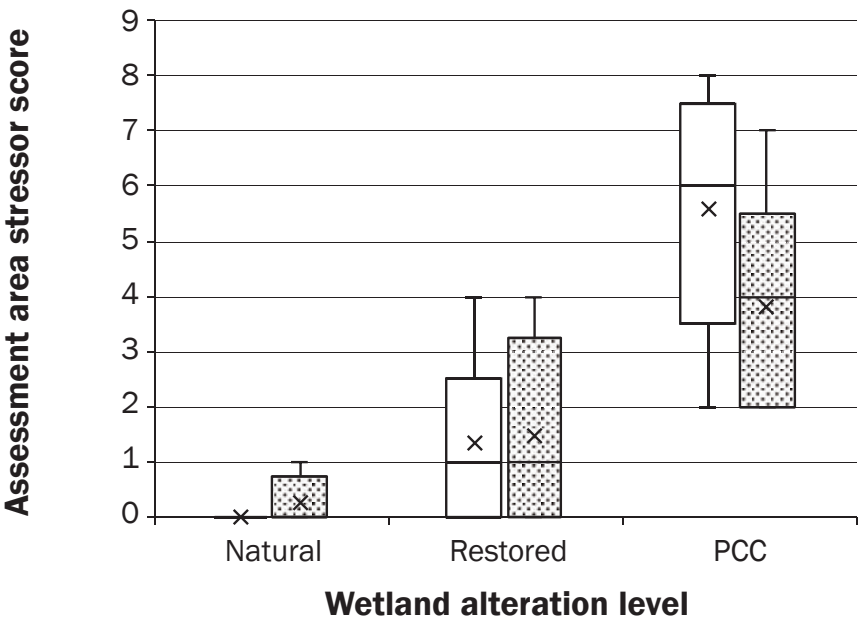

(c)

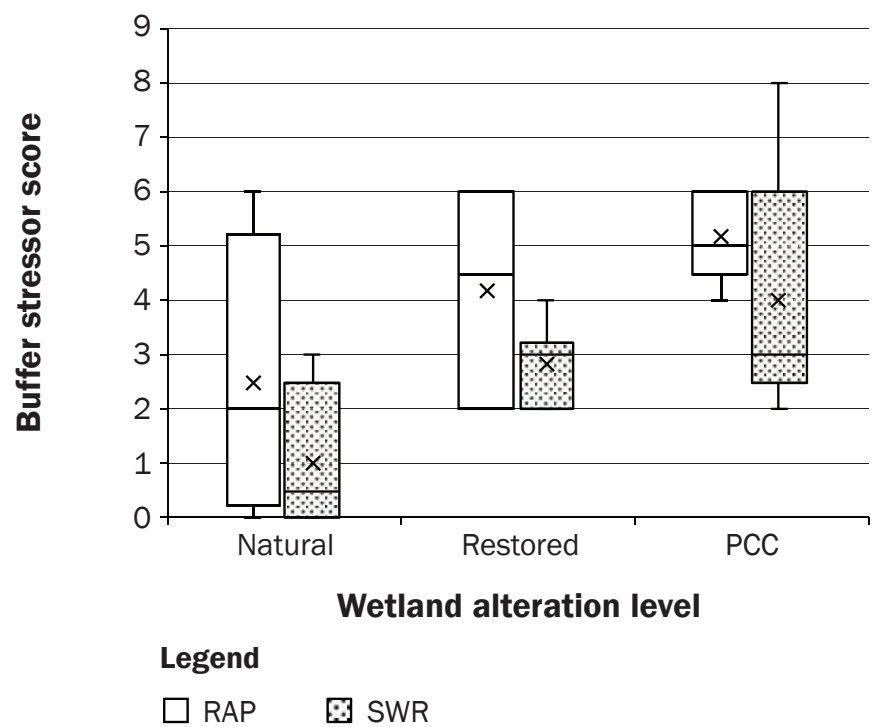

This was also indicated by the lack of significance among the results of the LDI and the individual landscape components analyzed. However, as the landscape analysis was conducted at a coarser scale than the fieldbased observations, it may not be sensitive enough to detect smaller areas of influential land cover. Further investigation should be undertaken to determine if functions in depressional wetlands in the agricultural Coastal Plain are controlled more by the stressors in the immediate assessment area or influence from the surrounding landscape. This has implications for restoration, as the continued presence of stressors within or nearby a restored wetland may prevent it from attaining functional goals of a restoration plan if these stressors are not considered.

Microtopographic transects did not reveal significant differences among size classes and along the alteration gradient. The total average count of depressions per transect was also insignificant, with highest counts being observed in restored wetlands and the lowest counts within natural wetlands. Natural wetlands had the lowest average range across the size classes and contain almost all instances of microtopographic changes $>45 \mathrm{~cm}$ (the only observation of this size class outside of natural wetlands was observed in one transect of a restored wetland). In this case, distribution of counts may be more important than the total counts. This variability suggests further study should take place to better quantify assessment of this function, but it does point out a lack of microtopographic variation in altered sites.

Woody debris measurements in natural wetlands had the highest average counts per transect, though there was not a significant difference between the alteration levels for debris $>40 \mathrm{~cm}$. This was likely due to the absence of proximal large diameter trees at most sites, even in the forested natural wetlands. The lack of adjacent streams at natural wetlands also provided few means by which this debris could be transported. PCCs had slightly more small-class woody debris (1 to $12 \mathrm{~cm}$ and 12 to $40 \mathrm{~cm}$ ) than restored wetlands, potentially due to the presence of early succession woody plants on the banks of PCC ditches. It was observed that the permanent inundation and active management of the restored wetlands resulted in primarily herbaceous vegetation at restoration sites, with some sites possibly too young to have yet established adequate woody vegetation for debris input (McFarland et al. 2016). Though significantly different, the results of restored 
Table 4

Results of the landscape analyses within $1 \mathrm{~km}$ radius circle centered on each wetland.

\begin{tabular}{lcclcl}
\hline $\begin{array}{l}\text { Restoration } \\
\text { level }\end{array}$ & LDI & Forest (\%) & Agriculture (\%) & Development (\%) & $\begin{array}{l}\text { Road density } \\
\left(\mathbf{k m ~} \mathbf{~ k m}^{-2}\right)\end{array}$ \\
\hline PCC & 3.74 & 8.49 & 39.29 & 6.08 & 3.35 \\
& 3.90 & 20.56 & 53.11 & 5.62 & 2.26 \\
& 4.14 & 11.60 & 46.04 & 13.00 & 3.48 \\
& 4.20 & 8.78 & 52.34 & 7.29 & 3.06 \\
& 4.71 & 4.59 & 51.55 & 16.21 & 6.23 \\
\hline Restored & 2.81 & 4.04 & 25.01 & 5.42 & 4.46 \\
& 3.27 & 12.48 & 36.79 & 2.78 & 1.98 \\
& 3.88 & 15.46 & 43.91 & 2.09 & 1.08 \\
& 4.34 & 5.94 & 62.94 & 3.07 & 1.19 \\
& 4.40 & 7.72 & 52.73 & 10.62 & 3.13 \\
& 4.41 & 13.28 & 54.49 & 12.27 & 4.08 \\
\hline Natural & 3.05 & 16.76 & 36.77 & 2.61 & 0.66 \\
& 3.40 & 14.12 & 41.46 & 6.23 & 1.76 \\
& 4.03 & 9.44 & 55.94 & 3.59 & 1.19 \\
& 4.22 & 15.92 & 50.10 & 12.10 & 3.97 \\
\hline
\end{tabular}

Notes: LDI = Landscape Diversity Intensity Index. PCC = prior-converted cropland.

\section{Figure 6}

Average habitat suitability index (HSI) scores computed for each wetland condition by species. Habitat types were analyzed in three vegetative categories from left to right: open water (bullfrog, Lithobates catesbeianus; muskrat, Ondatra zibethicus), emergent/scrub-shrub (meadow vole, Microtus pennsylvanicus; red-winged blackbird, Agelaius phoeniceus; common yellowthroat, Geothlypis thrichas; American woodcock, Philohela minor; green-backed heron, Butorides striatus), and forested wetland (wood duck, Aix sponsa; wood frog, Rana sylvatica; red-backed vole, Clethriononmys gapperi).

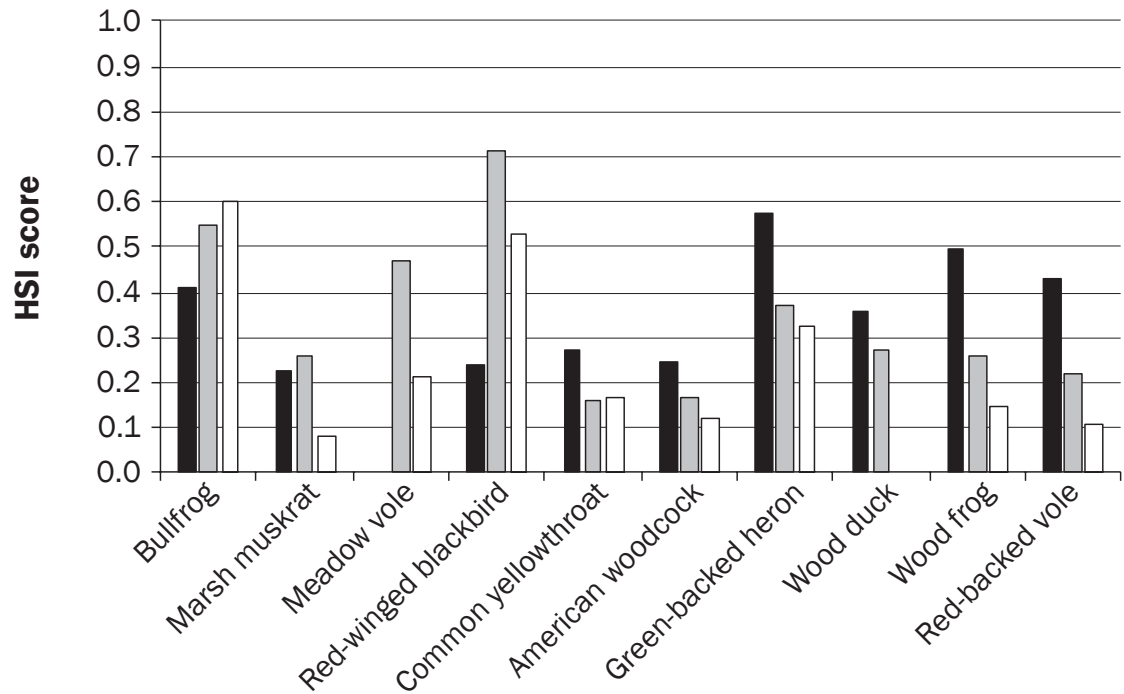

Legend

Species (common name)

- Natural $\square$ Restored $\square$ Prior-converted croplands

wetlands and PCCs were relatively close. The results suggest that natural sites are performing functions related to woody debris (e.g., habitat provisioning and nutrient cycling) at a higher rate than the rest of the alteration gradient.

HSI results indicate an increase in habitat quality and complexity in less altered sites. PCCs scored lowest across 9 of the 10 species evaluated. Restored sites were outperformed by natural wetlands for species adapted for forested environments, but had higher quality habitat scores for species using emergent and scrub-shrub habitats. Though the HSI does not provide a direct overall score to compare, one would expect wetlands in this ecoregion to eventually become forested through succession if human alteration was absent (Tiner 2005). Given the improvement in habitat scores from PCCs to restored wetlands for emergent and scrub-shrub habitats and restored wetlands to natural wetlands for forested habitat, the HSI supports the findings of the W-PAWF.

The significantly different gradient of soil compaction across the alteration gradient was likely the result of land management within the wetlands. The higher median values of restored wetlands compared to natural wetlands is likely due to restoration activities, including excavation, that lead to increased resistance (Bishel-Machung et al. 1996; Campbell et al. 2002). Bantilan-Smith et al. (2009) reported similar results where higher soil bulk density in restored and created wetlands compared to natural wetlands was attributed to increased resistance resulting from construction. PCCs also had higher soil resistance than natural wetlands, which was likely attributed to heavy agricultural machinery that led to soil compaction.

The median MP values of natural and restored wetlands approached excess $\mathrm{P}$ availability levels, potentially indicating excess nutrients are applied to the region under study. The median MP value for PCCs greatly exceeded $\mathrm{P}$ needs for crops typically grown in the study area. High nutrient loadings are known to shift the composition of species in wetlands, with species such as cattail (Typha sp.), duckweed (Lemna sp.), and common reed (Phragmites sp.) becoming aggressive and/or dominant during the eutrophication process (USEPA 2002). This suggests that both natural and restored wetland ecosystems within the studied region may enhance invasion success of nonnative or aggressive plants. This behavior may be beneficial for nutrient 


\section{Figure 7}

Boxplot of (a) soil compaction, (b) Mehlich phosphorus, and (c) total phosphorus results. Boundaries of the boxes represent the 25 th and 75 th percentiles and the horizontal line within the box represents the median. PCC is prior-converted cropland.

(a)

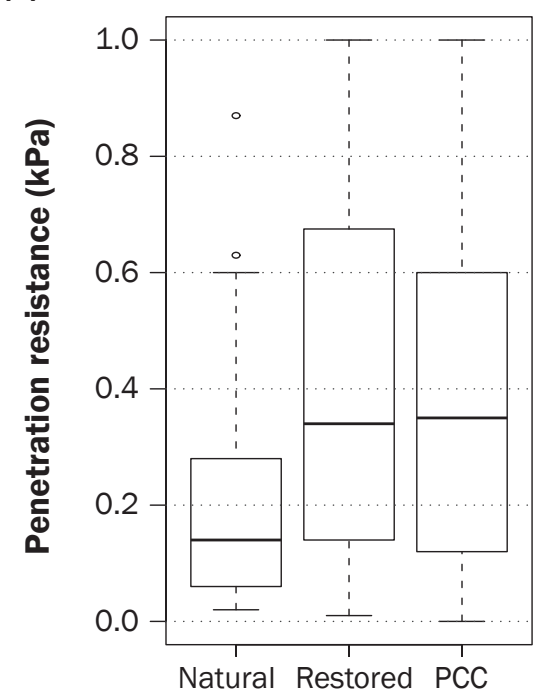

Wetland alteration level (b)

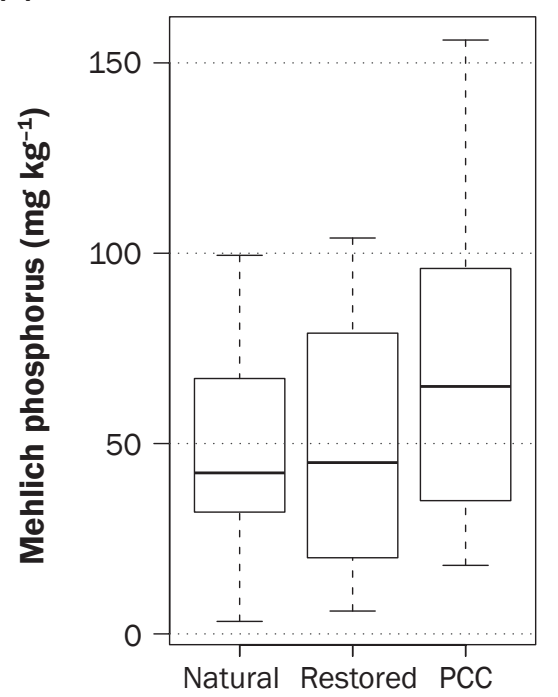

Wetland alteration level (c)

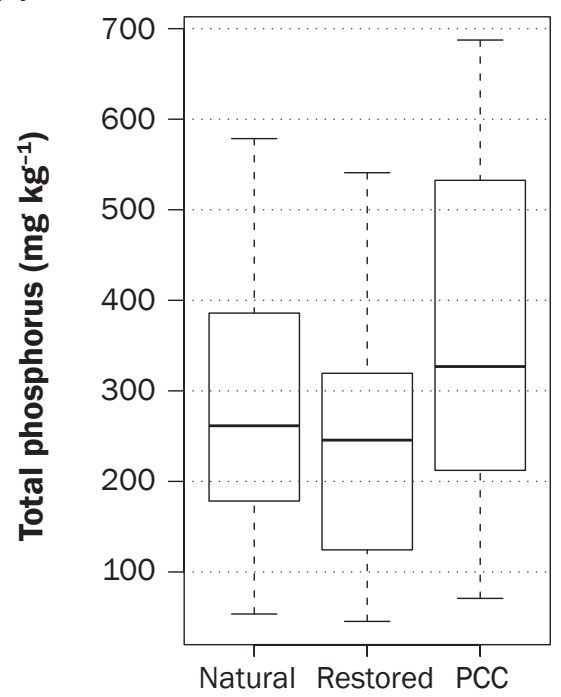

Wetland alteration level retention and/or transformation functional goals, but potentially detrimental when biodiversity is prioritized. These species were observed in some PCCs and restored wetlands, but not in natural wetlands.

W-PAWF Applicability in Wetland Restoration Assessment. The W-PAWF was able to detect functional differences within the restored wetland category and showed the broad range of functional assemblages and performance that these wetlands exhibit. The total index revealed restored site scores spanned from those of PCCs to one site outscoring a natural wetland. Data were unavailable to determine if site maturity or design played a factor in the functional capability of the sites. However, results of the related field assessments support the results of the W-PAWF and show its strong potential for use in this application regardless of site history or desired trajectory.

Field observations of restored sites illustrate the potential to refine W-PAWF. For example, managing these sites may have large implications for functional potential. Those seemingly managed for wildlife and/or with actively managed vegetation, including buffers from other land use, scored highest in the biodiversity category. The observed conditions should be investigated further, as remote sensing may be able to detect signals of active management to enhance future W-PAWF assessments.
Furthermore, functions addressed through field-based methods are not necessarily covered by the remote assessment interpretation techniques. Microhabitat was observed in the microtopographic and CWD transects, but is not expressly a component of W-PAWF. The sensitivity of LiDAR data to microtopography in wetland environments should be explored in the future, as well as the utility of adding additional functions to W-PAWF. A review of the current methods also revealed that several stressors from the SWR and UMA RAP checklists (e.g., presence of roads, ditching, damming, mowing, and algal mats) can be observed in remotely sensed imagery (e.g., aerial photography and fine spatial resolution multispectral satellite imagery). Further evaluation of the field-based methods should be undertaken to determine whether remote assessment of these field-based measurements is possible.

In addition to field assessments, the incorporation of additional remote functional assessment methods may enhance W-PAWF. One such assessment is the HGM Classification and Functional Assessment system as implemented by Wardrop et al. (2011). This HGM assessment system, built from concepts similar to LLWW and W-PAWF, can remotely assess functions that are too generalized or absent from the W-PAWF system. For example, whereas restoration goals may incorporate a water quality or biogeochemical component, the W-PAWF was designed to be limited to the "nutrient transformation" function. In contrast, the HGM system can predict the presence/ absence of more specific functions, such as removal of inorganic nitrogen $(\mathrm{N})$ and retention of inorganic particulates. Though it does not have the capability to specify a potential functional performance rating, this presence/absence system can enhance the results of W-PAWF by providing a more complete assessment of functions targeted by restoration objectives. By documenting variations in wetland condition through land use analysis and modeling, in combination with selected field data, we believe a more detailed functional assessment can be developed that could include variable performance ratings that go beyond W-PAWF's current capabilities. Furthermore, Wardrop et al. (2011) links NRCS conservation practices to potential functional improvements, tying the functional assessment to application. This system, when integrated with the W-PAWF, could conceivably evaluate the potential for conservation practices to enhance an assessed function and inform decision-makers of the socioeconomic trade-offs relevant to conservation practice implementation.

Limitations. The W-PAWF is intended for use as a means for exploratory assessment at 
a broad scale (i.e., Level 1 landscape analysis). It is limited by the quality of remotely sensed data, land cover maps, and other ancillary data. For example, the NWI does not capture 4 of the 15 sites assessed in this study (three PCCs and one restored wetland). Exclusion of these types of wetlands could be due to targeted mapping area limits on the size of wetlands included within the data set, the age of the data set relative to the date of wetland restoration, and/or the fact that the data set was not designed to map PCCs.

The scope of this study limited the variability of wetland types that could be tested. The study's setting within the relatively flat Coastal Plain ecoregion and its predominately agricultural land use limited which functions can occur and their performance. The study also was limited to one HGM class (i.e., depression) and only natural, restored, and PCC alteration conditions. Due to the parameters of this pilot study, use should be restricted to the evaluation of depressions within the Coastal Plain of the Mid-Atlantic Region until further testing is undertaken.

Potential Development and Application. The W-PAWF provides a potential gradient of functional variety and performance and is designed to be used at watershed and regional scales. Once used for an initial inventory, change in functional variety and performance can be tracked over time. Use of remote sensing data also allows for potential historical functional assessments when such data are available. While this study was tested against three levels of the alteration gradient, an assessment could be adjusted to ranges of scores or categories appropriate to the goal of an assessment or regional variation.

One potential application of our index is to target potential wetland restoration sites. While the index cannot predict postrestoration levels on its own, a set of wetlands, whether an inventory across an entire watershed or a set of sites from interested landowners, could be evaluated to find wetlands where a desired function is impacted. The resulting W-PAWF index scores could be used to initially target potential sites (e.g., removing from consideration sites that would not benefit greatly from restoration or that would be too costly to restore), allowing restoration coordinators to save time and material associated with site visits, data collection, and analysis.

Alternative field measurement techniques should be explored for potential use in remote sensing data collection. The field-based meth- ods used in this assessment took a team of four people between two to four hours to complete, which is appropriate for a rapid assessment. However, the use of unmanned aerial vehicles (UAVs) could add data and value to these assessments, reducing time in the field and providing up-to-date data for analysis. Real time imagery and LiDAR collection have the potential to replace time-intensive sampling, such as vegetation assessment and microtopographic transects.

Future research should attempt to address the limitations of this study. The variability introduced by the inclusion of additional wetlands types, geographic regions, and land use patterns may deviate from the patterns observed in this study. Further development also should investigate the use of a simple index for scoring, as increasing variability and number and performance of functions investigated may require the inclusion of additional functional performance levels, variable weighting, and the incorporation of semiquantitative measures in scoring.

\section{Summary and Conclusions}

W-PAWF was found to be an effective means of remotely assessing functional variety and performance level in depressional wetlands along a gradient of conditions in the MidAtlantic Coastal Plain. However, the use of field-based assessment methods and comparison with another remote functional assessment method demonstrate the need for additional refinement and improvement to the system to remotely assess a greater range of potential functional goals in wetland restoration practices. Evaluations conducted in the study show the potential for several of these functions to be remotely assessed and adopted into the W-PAWF assessment. Future studies incorporating additional wetland functions, HGM classifications, and geographic regions are under consideration to address the limitations of this study.

\section{Acknowledgements}

This material is based upon work supported in part by the USDA Agricultural Research Service in Beltsville, Maryland, under Agreement No. 58-8042-7-036 as a component of the Mid-Atlantic Regional Wetland Conservation Effects Assessment Project (MIAR-CEAP). Additional financial support was provided to the senior author by the Penn State Department of Geography and Riparia.Thanks to Bill Effland (NRCS) for financial support and advice, Emily Kerstetter and Collin Charnoff for their assistance in the field, Denice Wardrop, Sarah Chamberlain, and Corina Fernandez of
Riparia for their guidance, Lou Saporito (USDA ARS) for soil analyses, and the landowners who participated in the study. Any opinions, findings, and conclusions or recommendations expressed in this publication are those of the authors and do not necessarily reflect the views of the awarding agencies.

\section{Disclaimer}

USDA is an equal opportunity provider, employer, and lender. Any use of trade, firm, or product names is for descriptive purposes only and does not imply endorsement by the US Government.

\section{References}

Bantilan-Smith, M., G.L. Bruland, R.A. MacKenzie, A.R. Henry, and C.R. Ryder. 2009. A comparison of the vegetation and soils of natural, restored, and created coastal lowland wetlands in Hawai'i. Wetlands 29:1023-1035

Bishel-Machung, L., R.P. Brooks, S.S.Yates, and K.L. Hoover 1996. Soil properties of reference wetlands and wetland creation projects in Pennsylvania. Wetlands 16:532-541.

Brinson, M.M. 1993a. Changes in the functioning of wetlands along environmental gradients. Wetlands 13:65-74

Brinson, M.M. 1993b. A Hydrogeomorphic Classification for Wetlands. Wetlands Research Program Technical Report WRP-DE-4. Washington, DC: US Army Corps of Engineers.

Brinson, M.M. 1995. The HGM approach explained. National Wetlands Newsletter 17:7-13.

Brooks, R., M. McKenney-Easterling, M. Brinson, R. Rheinhardt, K. Havens, D. O’Brien, J. Bishop, J. Rubbo, B. Armstrong, and J. Hite. 2009. A Stream-WetlandRiparian (SWR) index for assessing condition of aquatic ecosystems in small watersheds along the Atlantic slope of the eastern US Environmental Monitoring and Assessment 150:101-117

Brooks, R.P. (ed.). 2004. Monitoring and Assessing Pennsylvania Wetlands. Final Report for Cooperative Agreement No. X-827157-01, between Penn State Cooperative Wetlands Center, Pennsylvania State University, University Park, PA and US Environmental Protection Agency, Office of Wetlands, Oceans, and Watersheds, Washington, DC. University Park, PA: Penn State Cooperative Wetlands Center.

Brooks, R.P., M.M. Brinson, K.J. Havens, C.S. Hershner, R.D. Rheinhardt, D.H. Wardrop, D.F. Whigham, A.D. Jacobs, and J.M. Rubbo. 2011. Proposed hydrogeomorphic classification for wetlands of the Mid-Atlantic Region, USA. Wetlands 31:207-219.

Brooks, R.P., and N.A. Gebo. 2013. Wetlands restoration and mitigation. In Mid-Atlantic Freshwater Wetlands: Advances in Science, Management, Policy, and Practice, eds. R.P. Brooks and D.H. Wardrop, 421-440. New York: Springer Science+Business Media.

Brooks, R., K. Havens, H. Ingram, K.Angstadt, D. Stanhop, and A. Jacobs. 2013. Creating a Unified Mid-Atlantic Rapid Assessment Protocol for Wetlands. In Mid-Atlantic State 
Regional Wetlands Assessment Final Report, Chapter 2 9-26. State College, PA: Pennsylvania State University and Virginia Institute of Marine Science.

Brooks, R.P., and D.J. Prosser. 1995. Habitat suitability index models and wildlife community habitat profiles for use in Pennsylvania wetlands. University Park, PA: The Pennsylvania State University.

Brown, M.T., and M.B.Vivas. 2005. Landscape development intensity index. Environmental Monitoring and Assessment 101:289-309.

Campbell,D.A.,C.A.Cole, and R.P.Brooks. 2002.A comparison of created and natural wetlands in Pennsylvania, USA. Wetlands Ecology and Management 10(1):41-49.

Chamberlain, S.J., and R.P. Brooks. 2016. Testing a rapid Floristic Quality Index on headwater wetlands in central Pennsylvania, USA. Ecological Indicators 60:1142-1149.

Chamberlain, S.J., and H.M. Ingram. 2012. Developing coefficients of conservatism to advance floristic quality assessment in the Mid-Atlantic region. The Journal of the Torrey Botanical Society 139:416-427.

Costanza, R., R. Arge, R. de Groot, S. Farber, M. Grasso, B. Hannon, K. Limburg, S. Naeem, R.B. O'Neill, J. Paruelo, R.G. Raskin, P. Sutton, and M. van den Belt. 1997. The value of the world's ecosystem services and natural capital. Nature 387:253-260.

Cowardin, L.M., V. Carter, F.C. Golet, and E.T. LaRoe. 1979. Classification of Wetlands and Deepwater Habitats of the United States. FWS/OBS-79/31. Washington, DC: US Department of the Interior, US Fish and Wildlife Service.

Dahl, T.E. 1990. Wetlands losses in the United States 1780's to 1980's. Washington, DC: US Department of the Interior, Fish and Wildlife Service.

Dahl, T.E. 2000. Status and trends of wetlands in the conterminous United States 1986 to 1997. Washington, DC: US Department of the Interior, Fish and Wildlife Service.

Dahl, T.E. 2006. Status and trends of wetlands in the conterminous United States 1998 to 2004. Washington, DC: US Department of the Interior, Fish and Wildlife Service.

Dahl, T.E. 2011. Status and Trends of Wetlands in the Conterminous United States 2004 to 2009. Washington, DC: US Department of the Interior, Fish and Wildlife Service.

FGDG (Federal Geographic Data Committee). 2013. Classification of wetlands and deepwater habitats of the United States, 2nd edition. FGDC-STD-004-2013. Washington, DC: Wetlands Subcommittee, Federal Geographic Data Committee and US Fish and Wildlife Service.

Kentula, M.E., R.P. Brooks, S.E. Gwin, C.C. Holland, A.D. Sherman, and J.C. Sifneos. 1992. An Approach to Improving Decision-Making in Wetland Restoration and Creation. Boca Raton, FL: CRC Press.

Kimbrough, D.E., and J.R. Wakakuwa. 1989. Acid digestion for sediments, sludges, soils and solid wastes: A proposed alternative to EPA SW 8466 method 3050. Environmental Science \& Technology 23:898-900.
Lang, M., G. McCarty, T. Ducey, P. Hunt, J. Miller, M. Rabenhorst, A. Baldwin, D. Fenstermacher, M. Yepsen, E. McFarland, A. Sharifi, C. Church, J. Denver, S. Ator, J. Mitchell, D. Whigham, and M. Walbridge. 2015. Effects and Effectiveness of USDA Wetland Conservation Practices in the Mid-Atlantic Region: A Report on the Conservation Effects Assessment Project Mid-Atlantic Regional Wetland Assessment 2008-2015. Washington, DC: USDA Natural Resources Conservation Service.

Lee, S., G.W. McCarty, G.E. Moglen, M.W. Lang, A.M. Sadeghi, T.R. Green, I.Y. Yeo, and M.C. Rabenhorst. 2018. Effects of subsurface soil characteristics on wetland-groundwater interaction in the coastal plain of the Chesapeake Bay watershed. Hydrological Processes doi:10.1002/hyp.13326.

McFarland, E.K., M. LaForgia, M. Yepsen, D.F. Whigham, A.H. Baldin, and M. Lang. 2016. Plant biomass and nutrients $(\mathrm{C}, \mathrm{N}$ and $\mathrm{P})$ in natural, restored, and prior converted depressional wetlands in the Mid-Atlantic Coastal Plain, U.S. Folia Geobotanica 51:267-283.

McLaughlin, D.L., and M.J. Cohen. 2013. Realizing ecosystem services: Wetland hydrologic function along a gradient of ecosystem condition. Ecological Applications 23:1619-1631.

Mehlich, A. 1984. Mehlich No. 3 soil test extractant: A modification of Mehlich No. 2 extractant. Communications in Soil Science and Plant Analysis 15:1409-1416.

Menne, M.J., I. Durre, B. Korzeniewski, S. McNeal, K. Thomas, X. Yin, S. Anthony, R. Ray, R.S. Vose, B.E. Gleason, and T.G. Houston. 2012a. Global Historical Climatology Network - Daily (GHCN-Daily), Version 3. GREENSBORO 1.4 ENE, MD, United States; Station Code: US1MDCL0009. Silver Spring, MD: NOAA National Climatic Data Center. https://climexp. knmi.nl/gdenprcp.cgi?WMO=US1MDCL0009.

Menne, M.J., I. Durre, R.S. Vose, B.E. Gleason, and T.G. Houston. 2012b. An overview of the Global Historical Climatology Network-Daily database. Journal of Atmospheric and Oceanic Technology 29:897-910.

MAWWG (Mid-Atlantic Wetland Workgroup). n.d. Floristic Quality Assessment Calculator. Mid-Atlantic Wetland Workgroup. State College, PA: The Pennsylvania State University. http://mawwg.psu.edu.

Millennium Ecosystem Assessment. 2005. Ecosystems and Human Well-Being: Wetlands and Water Synthesis. Washington DC: World Resources Institute.

Miller, S.J., and D.H. Wardrop. 2006. Adapting the floristic quality assessment index to indicate anthropogenic disturbance in central Pennsylvania wetlands. Ecological Indicators 6:313-326.

Miller, S.J., D.H. Wardrop, W.M. Mahaney, and R.P. Brooks. 2006. A plant-based index of biological integrity (IBI) for headwater wetlands in central Pennsylvania. Ecological Indicators 6:290-312.

Minitab Inc. 2017. Minitab 18 Version 18.1. State College, PA:The Pennsylvania State University.
Mitsch,W.J., and J.G. Gosselink. 2000. The value of wetlands: Importance of scale and landscape setting. Ecological Economics 35:25-33.

R Core Team. 2013. R: A language and environment for statistical computing. Vienna, Austria: R Foundation for Statistical Computing.

Tiner, R.W. 2003. Correlating enhanced National Wetlands Inventory data with wetland functions for watershed assessments: A rationale for northeastern U.S. wetlands. Hadley, MA: US Fish and Wildlife Service, Northeast Region.

Tiner, R.W. 2005. Assessing cumulative loss of wetland functions in the Nanticoke River watershed using enhanced National Wetlands Inventory data. Wetlands 25:405-419.

Tiner, R.W. 2014. Dichotomous Keys and Mapping Codes for Wetland Landscape Position, Landform, Water Flow Path, and Waterbody Type Descriptors: Version 3.0. Hadley, MA: US Fish and Wildlife Service, National Wetlands Inventory Program, Northeast Region.

USEPA (US Environmental Protection Agency). 2002. Methods for Evaluating Wetland Condition:VegetationBased Indicators of Wetland Nutrient Enrichment. EPA-822-R-02-024. Washington, DC: Office of Water, US Environmental Protection Agency.

Wardrop, D.H., A.K. Glasmeier, J. Peterson-Smith, D. Eckles, H. Ingram, and R.P. Brooks. 2011. Wetland ecosystem services and coupled socioeconomic benefits through conservation practices in the Appalachian Region. Ecological Applications 21:93-115.

Weller, D.E., M.N. Snyder, D.F. Whigham, A.D. Jacobs, and T.E. Jordan. 2007. Landscape indicators of wetland condition in the Nanticoke River watershed, Maryland and Delaware, USA. Wetlands 27:498-514.

Whigham, D.F., A.D. Jacobs, D.E. Weller, T.E. Jordan, M.E. Kentula, S.F.Jensen, and D.L.Stevens Jr. 2007. Combining HGM and EMAP procedures to assess wetlands at the watershed scale: Status of flats and non-tidal riverine wetlands in the Nanticoke River watershed, Delaware and Maryland (USA). Wetlands 27:462-478.

Yepsen, M., A.H. Baldwin, D.F. Whigham, E. McFarland, M. LaForgia, and M. Lang. 2014.Agricultural wetland restoration on the USA Atlantic Coastal Plain achieve diverse native wetland plant communities but differ from natural wetlands. Agriculture, Ecosystems and Environment 197:11-20.

Zedler, J.B., and S. Kercher. 2005. Wetland resources: Status, trends, ecosystem services, and restorability. Annual Review of Environment and Resources 30:39-74. 